\title{
Does Prospect Theory Warrant a Paradigm Shift In THE ECONOMICS OF Risk? ${ }^{1}$
}

Powell L Mohapi

Department of Economics, National University of Lesotho

This paper assesses whether a paradigm shift should be made from expected utility framework to prospect theory framework - in the economics of choice under risk. A brief overview of the subject is outlined, starting with expected utility theory and noting its descriptive limitations. Proposed theories to make up for these limitations is also provided. Prospect theory emerged as the most serious challenger to expected utility theory. A review of some descriptive predictions of prospect theory, suggests that there is no scientific reason why expected utility should not be ousted from dominance by prospect theory. The shift to prospect theory however is not without costs. Conceptual complexities and non-universality of application associated with prospect theory should be embraced with the shift while not entirely abandoning expected utility theory.

JEL D81

"In a series of influential articles, Kahneman and Tversky (1979, 1986, 1992) suggest that economic agents do not maximize the expected value of Von Neumann-Morgenstern utility function, but behave according to a set of rules collectively known as prospect theory.”- Shumway (1997: 1)

1

\section{Introduction}

The ongoing debate in the economics profession, in particular the economics of choice under risk, underpins the subject of this essay. The debate concerns the continued supremacy of the classical expected utility theory (EUT) in the light of a growing body of evidence, albeit experimental, that individuals do not maximize the expected utility (EU). In the light of this evidence a proliferation of theories, collectively known as non-EU theories, has been put forth in an attempt to provide a better descriptive picture of observed behaviour under risk. The development of nonEU models has a daunting task of coming up with a model that will oust the EUT from its dominant position. The ultimate influence of the non-EU models on the profession at large will depend on whether they can be used to conduct analyses of standard economic decisions under risk in a manner that can match or at least approximate the elegance and power of the EU hypothesis (Machina, 1989; Epstein, 1992).

Of the numerous non-EU theories proposed in the wake of EUT descriptive inaccuracies prospect theory (PT) seems to be the most promising. PT is conceptually superior, grounded in the psychology of agent decision making process and being descriptively robust. Its success in explaining phenomena where EUT systematically fails raises the question whether a paradigm shift in theoretical analysis of choice under risk is warranted. Granted, the economics profession has witnessed several paradigm shifts in several of its fields with the universally known example being the shift from adaptive expectations to rational expectations in macroeconomics. In attempting to assess whether a paradigm shift from EUT denominated analysis to PT denominated analysis 
in the economics of risk the paper proceeds by outlining the two theories and then making a head-to-head comparison to come to a conclusion. In section II the EUT is outlined along with its well known descriptive inaccuracies, while section III provides a cursory presentation of some prominent nonEU theories. A relatively in-depth treatment of PT is a subject of section IV. Some predictions of PT are provided in section V. Section VI is a head-to-head comparison EUT and PT in terms of the implied costs and benefits of the proposed paradigm shift. Section VII concludes the essay.

\section{2}

\section{The expected utility theory}

EUT is a result Daniel Bernoulli's (1738/1954) resolution of the St. Petersburg paradox ${ }^{2}$ coupled with the work of von Neumann and Morgenstern (1944) who showed that the EU hypothesis could be derived from a set of few appealing axioms, rendering it to be a rational decision criterion. A heuristic specification of the theory is provided below.

Let $\left\{x_{p}, x_{2}, \ldots, x_{n}\right\}$ be a set of monetary prizes or outcomes and define a lottery $X=\left(x_{1}, p_{1}\right.$; $\left.x_{2}, p_{2}, \ldots, x_{n} p_{n}\right)$ as a finite probability distribution over outcomes with $p_{i} \in[0,1]$ and $\sum_{i=1}^{n} p_{i}=1$. A lottery $X$ yields outcome $x_{i}$ with probability $p_{i}$ for $i=1,2, \ldots, n$. Denote by $A$ the set of all prizes/ outcomes and by $L$ the set of all lotteries. Let $\geq$ be a preference relation defined over lotteries. $\geq$ $(>$ ) denotes a weak (strong) preference relation. For some lotteries $X$ and $Y, X \geq Y$ and $Y \geq X$ imply $X \sim Y$. Furthermore let $\geq$ satisfy the following axioms:

A1. Completeness: For any two lotteries $X$ and $Y$ either $X>Y, Y>X$ o r $X \sim Y$.

A2. Transitivity: For any three lotteries $X, Y$ and $Z$, if $X>Y$ and $X>Z$ then $X>Z$.

A3. Archimedean axiom: If lotteries $X, Y$ and $Z$ are such that $X>Y>Z$ then there exist some $\alpha, \psi \in(0,1)$ such that $\alpha X+(1-\alpha) Z$ $>Y$ and $Y>\psi X+(1-\psi) Z$.

A4. Independence axiom: If $X>Y$ then $(X, \alpha$; $Z, 1-\alpha)>(Y, \alpha ; Z, 1-\alpha)$ for all $\alpha \in(0,1)$.
Completeness and transitivity are familiar from conventional micro-theory. The Archimedean axiom serves the purpose served by continuity in conventional micro-theory. It effectively states that for any three lotteries that are strictly preferred to each other and are preference ordered, there exist some compound lotteries that are convex combinations of the most preferred and the least preferred lotteries such that one is strictly preferred to the middle lottery and the middle lottery is strictly preferred to the other. The independence axiom states that preferences between lotteries $X$ and $Y$ remains unaffected if they are each combined in the same way with the third lottery $Z$.

Preferences satisfying A1-A4 can be represented by the utility function

$U(X)=\sum_{i=1}^{n} p_{i} u\left(x_{i}\right)$

Where $U: L \rightarrow \Re$ is the utility function representing preferences over lotteries and $u: A \rightarrow \Re$ is the utility function representing preferences over outcomes. $U($.) satisfying (1) is the famous von Neumann-Morgenstern (VNM) utility function. The VNM utility function thus can be represented as a mathematical expectation of utilities over outcomes hence the name expected utility.

The VNM axiomatic characterisation of Bernoulli's cardinal specification rendered it ordinal and as a result attractive to economists. Since risk is common in economics, EUT was able to lend itself as an elegant modelling device in situations involving risk. Even some cardinal features of Bernoulli utility measure were accepted by economists, the case in point being risk aversion. In order to compare degrees of risk aversion between agents cardinal utility is needed.

VNM EUT has since become the dominant hypothesis in the mainstream economics of risk. Several fundamental areas of economics are based on EUT. Starmer (2000) points to two such areas: game theory and the analysis of dynamic choice. EUT ensures the existence of Nash equilibrium in game theory while in dynamic choice problems sequential choices are dynamically inconsistent without EU preferences (Starmer, 2000). Classical finance theory is also underpinned by EU preference 
structure. In fact Campbell, Lo and MacKinlay (1997: 3) sum this up with the words:

What distinguishes financial economics is the central role that uncertainty plays in both financial theory and its empirical implementation. The starting point of every financial model is the uncertainty facing investors, and the substance of every financial model is the impact of uncertainty on the behaviour of investors and ultimately on market prices.

Despite its usefulness and popularity in theoretical modeling EUT has systematically failed to accurately explain observed behaviour. Some prominent inaccuracies of EUT are stated below.

\subsection{Descriptive inaccuracies of EUT}

EUT can exhibit either risk averse, risk neutral or risk seeking preferences - only one profile at a time. The first doubt of EUT predictive ability in this regard was raised by Friedman and Savage (1948) who noted that the coexistence of insurance and gambling appeared anomalous to this theory.

There is an abundance of experimental evidence, which reflects violations of the EUT axioms, particularly the independence axiom. One of the earliest examples of systematic violations of the independence axiom of the EUT is the well-known Allais paradox (Allais, 1953). The Allais paradox is a special case of a more general empirical pattern known as the common consequence effect noted among others by Moskowitz (1974), Slovic and Tversky (1974) and Kahneman and Tversky (1979). Summary descriptions of this phenomenon can be found in Starmer (2000) and Machina (1987) with the latter author providing some intuitive explanation.

A closely related phenomenon, also stemming from Allais (1953), is the common ratio effect. The common ratio effect is the observation that the more risky of the two lotteries becomes relatively more attractive when the probability of winning is reduced by equal proportion in both lotteries (Prelec, 1998). It is observed in choices among pairs of problems of the form: $X=(x, p ; 0,1-p)$ and $Y$ $=(y, \lambda p ; 0,1-\lambda p)$ where $\lambda \in(0,1)$ and $y>x$. If $\lambda$ is constant EUT implies that preferences should not depend on the value of $p$. A number of studies however (Kahneman and Tversky, 1979; Loomes and Sugden, 1987; and Starmer and Sugden, 1989) reveal a tendency for individuals to switch their choices from $y$ to $x$ as $p$ falls. The common consequence and the common ratio effects are violations of the independence axiom of the EUT.

Another class of the EUT preference violations concerns the elicitation of choices. The first phenomenon in this class is the preference reversal. In the classic experiment of this phenomenon by Lichtenstein and Slovic (1971) subjects were required to perform two tasks. Firstly, the subjects were asked to choose between two lotteries, the \$-bet (which offered a small chance of winning a good prize) and the P-bet (which offered a large chance of winning a small prize). The second task required subjects to assign monetary values, $\mathrm{M}($.$) , to the two$ lotteries as if they were to sell them. The first task revealed $\mathbf{P}>\mathbf{\$}$ while the second revealed $\mathbf{M}(\$)>\mathbf{M}(\mathbf{P})$. The robustness of this phenomenon is confirmed in Lichtenstein and Slovic (1973) and Grether and Plott (1979). Tversky and Thaler (1990) provide a review of further evidence on preference reversals.

The second phenomenon is the framing (context) effects. According to this phenomenon, the way in which objects of choice are described has a dramatic influence on choice. One widely cited example of this is the "Asian disease" example of Tversky and Kahneman (1981) in which identical choices are framed in terms of lives saved to one group of subjects and lives lost to another group. Another example by Hershey and Schoemaker (1980) used the gambling and insurance frames as follows:

Gambling frame: 1a. A sure loss of $\$ 10$. 1b. $1 \%$ chance of losing $\$ 1,000$.

Insurance frame: 2a. Pay an insurance premium of $\$ 10$.

2b. Remain exposed to the hazard of losing $\$ 1,000$ with $1 \%$ chance. 
Both contexts present the choice between $u\left(w_{0}-\right.$ 10) and $0.01 u\left(w_{0}-1,000\right)+0.99 u\left(w_{0}\right)$ and EUT description invariance dictates that choices should be consistent. However 56 percent of 42 Hershey and Schoemaker subjects preferred a sure loss when the problem was presented in the gambling context versus 81 percent in the insurance context.

Another predictive error of EUT has been reported recently by Rabin (2000) and Rabin and Thaler (2001). Rabin (2000) provides a theorem which shows that the risk neutrality result for very small bets extends to modest bets as well. His calibration results show that if risk aversion is invoked in modest bets, as is often the case in the economics literature, then the implied risk aversion for large bets is unrealistically high. For instance an EUT maximizer who rejects a 50-50 bet losing $\$ 100$ and gaining $\$ 110$ will also reject a $50-50$ bet of losing $\$ 1,000$ and gaining any amount of money.

\section{3 \\ A Catalogue of non-expected utility theories}

The descriptive limitations of the EUT led to a wave of research in which a number of theories collectively referred to as non-EU theories were proposed. These theories can be classified into those that generalise EUT, mainly by relaxing the notion of linear probabilities, on one hand and those that are alternatives to EUT, which mainly abandon the rationality paradigm upon which EUT is based on the other. It is from this hunt of the EUT alternative - the theory would pass the ultimate test, which is near-accurate prediction of observed behavior - that PT emerged as the most promising model. A selection of non-EU theories is briefly reviewed before presenting the current version of PT in relative depth.

The well known of non-EU theories are PT (Kahneman \& Tversky, 1979; Tversky \& Kahneman, 1992), regret theory (Bell, 1982; Loomes \& Sudgen, 1982) and rank-dependent utility (RDU) theory (Quiggin, 1982). Regret theory, rank-dependent utility theory together with disappointment aversion theory (Gul, 1991) are briefly outlined below.

\subsection{Regret theory}

The intuition of regret theory is that the utility on a realized outcome also depends on what could have been the outcome had choice been made differently. That is, accompanying the resulting outcome from a decision is a psychological experience of either regret or rejoicing (Loomes \& Sugden, 1982). This is best illustrated by Bell's (1982) example of a farmer whose crop value (price per bushel) at harvest time two months away is uncertain. Suppose the price will either be $\$ 3$ or $\$ 7$ with equal probability. If the farmer is offered a sure $\$ 5$ upfront and accepts but it turns out that at harvest the crop price is $\$ 7$ then he will experience regret of having lost $\$ 2$. On the other hand if the price turns out to be $\$ 3$ then there will be rejoicing over the $\$ 2$ gain.

Regret theory has explained with success some of the paradoxes of EUT. In both Loomes and Sugden (1982) and Bell (1982) the classical paradox of coexistence of insurance and gambling (Friedman and Savage, 1948) is well predicted by regret theory. The former authors also show that the Allais' paradoxes (common consequence and common ratio effects) are well explained by regret theory while in another paper (Loomes \& Sugden, 1983) they point to regret as the rationale for preference reversals ${ }^{3}$.

\subsection{Disappointment aversion theory}

Disappointment aversion developed among others by Gul (1991) is based on the idea that peoples' expectations are formed endogenously for each gamble and that they experience disappointment (elation) if the outcome of the gamble is less than (greater than) the expected outcome. The theory is compactly captured by the value function proposed by Jia, Dyer and Butler (2001).

$$
v\left(x_{i}\right)=x_{i}+\left\{\begin{array}{l}
e\left(x_{i}-E x_{i}\right) \text { if } x_{i} \geq E x_{i} \\
d\left(x_{i}-E x_{i}\right) \text { if } x_{i}<E x_{i}
\end{array}\right.
$$

where $E x_{i}$ is the expected outcome ex ante while $x_{i}$ is the realized outcome ex post and $d>e>0$ reflecting that disappointment from a shortfall 
loom larger than elation from an excess of a corresponding magnitude.

\subsection{Rank-Dependent utility theory}

RDU first proposed by Quiggin (1982) is based on the intuition that the attention people pay to a particular outcome depends not only on the likelihood of the outcome being realized but also on how good or bad the outcome is as determined by its relative position of desirability with respect to other possible outcomes. The second intuition of RDU derives from the lessons of the Allais' paradoxes that people do not process probabilities linearly. RDU transforms cumulative probabilities of each outcome into decision weights. This weighting scheme gave RDU an edge over other models that used decision weights in that it satisfied the notion of stochastic dominance while decision weights based on transformation of simple probabilities did not satisfy this condition.

The fitting of RDU non-linear weighting scheme produces an inverted S-shaped curve, which implies that people pay much attention to extreme (best and worst) outcomes and relatively less attention to intermediate outcomes (Quiggin, 1982; Diecidue \& Wakker, 2001). This feature of RDU successfully explains the coexistence of gambling and insurance. Segal (1988) used RDU to explain the probabilistic insurance puzzle first observed by Tversky and Kahneman (1979). Because of its mathematical soundness, intuitive appeal and predictive ability RDU has been popular among economists relative to other nonexpected utility models. That is echoed in the words of Machina (1994: 1237) who referred to it "... as the most natural and useful modification of the classical expected utility formula".

\section{4}

\section{Prospect theory}

Kahneman and Tversky (1979) proposed PT as a positive theory of choice in the wake of EUT inaccuracies in explaining observed behaviour. PT comes in two versions: the original PT (OPT) of 1979 and its 1992 generalization, cumulative PT (CPT) by the same authors. OPT explained the major violations of EUT in choices between prospects involving a small number of outcomes, two nonzero outcomes to be specific.

One feature of OPT was to posit that choice is a two-phase process. In the first phase - the editing phase - people engage in some heuristic simplification of prospects coding them into gains and losses and other tasks such as combination, segregation and cancellation. In the second phase edited prospects are evaluated and then choice takes place. Kahneman and Tversky (1979) note that many preference anomalies like intransitivities, isolation effects and context effects result from the editing phase. The editing operations are carried out in no specific order. The order in which they are carried out is likely to depend on the structure of the prospect, its frame and the format of its display (Kahneman \& Tversky, 1979). In this way the editing phase does not lend itself to formal modeling. Due to this as well as the spirit of parsimony Kahneman and Tversky (1979) had to assume that the original formulation of the prospect leaves no room for further editing.

One of the major weaknesses of EUT is the notion of linearity in probabilities, which OPT attempted to get around by weighting outcomes with decision weights instead of their probabilities. The decision weights were monotonic transformations of outcome probabilities. The weighting scheme of transforming probabilities has two problems. Firstly, as noted above, it could not always satisfy stochastic dominance and secondly it could not be readily extended to prospects involving a large number of outcomes.

\subsection{Cumulative prospect theory}

To overcome the shortcomings of OPT Tversky and Kahneman (1992) put forth CPT. CPT embodies Quiggin's (1982) RDU while maintaining the basic features and intuition of OPT. The key features of CPT are: 
- The carriers of value (analogue of utility) are changes in asset positions instead of final assets. The changes are viewed relative to some reference point or status quo and are perceived as gains and losses if they are positive and negative respectively.

- The value function has a kink at the reference point and is steeper for losses than for gains. It is also concave above the reference point while convex below the reference point. The first feature of the value function is implied by the fact that losses loom larger than corresponding gains. This is the notion of loss aversion (Kahneman \& Tversky, 1979; Tversky \& Kahneman, 1991). The second feature is a result of diminishing sensitivity, which means that the impact of a change in one's asset position diminishes with the distance from the reference point.

- CPT also allows for different treatment for gains and losses. Decision weights for gains and losses need not be the same. The value function is a two part functional, one for gains and the other for losses.

\section{Figure 1}

The prospective value function
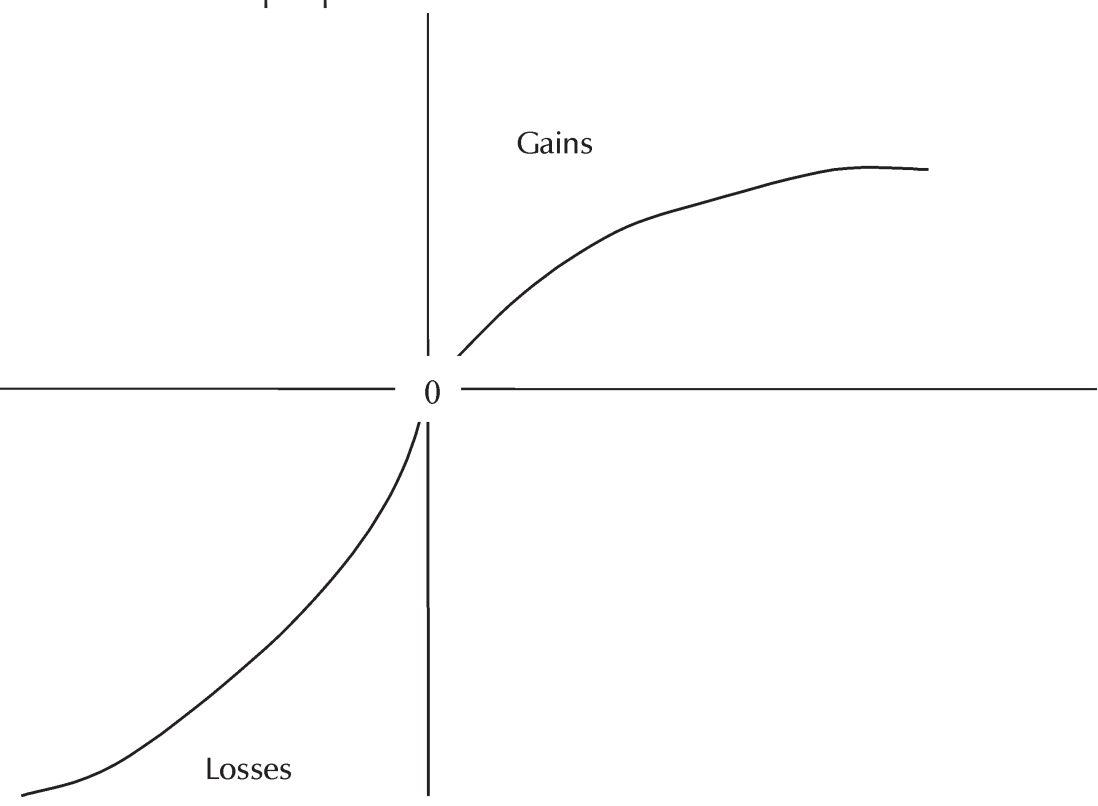

By embodying RDU, CPT inherits all the theoretical advantages of RDU that made it attractive to economists. However, CPT is more general than RDU by additionally allowing for reference-dependence and signdependence (Schmidt \& Zank, 2002a).

The CPT model presentation below closely follows Tversky and Kahneman (1992) and Neilson and Stowe (2002).

Suppose a lottery $X=\left(x_{-m}, p_{-m} ; \ldots\right.$; $\left.x_{o p} p_{0} ; \ldots ; x_{n} p_{n}\right)$ is composed of $m+n+1$ monetary outcomes which are rank ordered as $x_{-m}<\ldots<x_{0} \leqslant \ldots<x_{n}$. Let $x_{0}$ be the status quo and without loss of generality is set to zero (i.e. $x_{0}=0$ ) so that outcomes $\left\{x_{i}\right\}_{i=-m}^{-1}$ are losses and outcomes $\left\{x_{i}\right\}_{i=1}^{n}$ are gains. The utility value of the lottery $X$ under CPT is given by

$V(X)=\sum_{i=m}^{n} \pi_{i} v\left(x_{i}\right)$

Since CPT permits separate treatment of gains and losses $V(X)$ can be decomposed into

$V(X)=V^{+}(X)+V^{-}(X)$ 
Where $V^{+}$measures the contribution of gains and $V^{-}$measures the contribution of losses. Noting that $v\left(x_{0}\right)=v(0)=0$, the terms in equation (3) can then be written as

$V^{+}(X)=\sum_{i=0}^{n} \pi_{i}^{+} v\left(x_{i}\right)$ and $V^{-}(X)=\sum_{i=m}^{-1} \pi_{i}^{-} v\left(x_{i}\right)$

$\pi_{i}$ denotes the decision weight for outcome $x_{i}$ with $\pi_{i}^{+}\left(\pi_{i}^{-}\right)$being a decision weight applied to a gain (loss).

As noted earlier the utility function for outcome $x_{i}, v\left(x_{i}\right)$ under CPT is a two-part functional to permit gains and losses to be borne differently. Tversky and Kahneman (1992) proposed the form:

$$
v\left(x_{i}\right)= \begin{cases}x^{\alpha} & \text { if } x_{i} \geq 0 \\ -\lambda\left(-x_{i}\right)^{\alpha} & \text { if } x_{i}<0\end{cases}
$$

The value function $v\left(x_{i}\right)$ exhibits risk aversion over gains (by virtue of being concave above the reference point) and exhibits risk seeking over losses (since it is convex below the reference point). When faced with a choice between a sure gain and a prospect involving a probable loss and a probable gain, usually with a high upside risk, people tend to opt for a sure gain. On the other hand when faced with a choice between a sure loss and the prospect involving a probable gain and a probable loss, usually with a high downside risk, people tend to choose the prospect. These features have a loss aversion interpretation. In the risk aversion case, an impossible loss (sure gain) is preferred to a probable loss while in the risk seeking case a probable loss is preferred to a sure loss.

The curvature properties of $v\left(x_{i}\right)$ are ensured by the parameter $\alpha$ being restricted to be less than unity. The parameter $\lambda$ is the coefficient of loss aversion and is strictly greater than unity. These parameters were estimated from an experimental study reported in Tversky and Kahneman (1992) to be $\alpha=0.88$ and $\lambda=2.25$. These estimates have since been used in subsequent numerous studies.

Several axiomatizations of CPT can be found in the literature. To derive the general functional form conditions complex beyond the standard properties (continuity, weak ordering, stochastic dominance) are often required. Luce and Fishburn (1991) use a condition termed compound gamble and joint receipt. Tversky and Kahneman (1992), Wakker and Tversky (1993), Chateauneuf and Wakker (1999) and Schmidt (2003) use sign-dependent comonotonic tradeoff consistency. The conditions can be less complex if a particular parametric form for utility is desired. Schmidt and Zank (2002b) use a condition called independence of common increments to derive a model where utility is linear for gains and linear for losses. Wakker and Zank (2002) use a generalization of constant proportional risk aversion to incorporate losses and derive CPT with utility as a power function. Zank (2001) provides a model where utility is exponential or linear by requiring constant absolute risk aversion for gains and losses separately.

\subsection{The probability weighting function}

Decision weights are generated using a probability weighting function $w(p)$, in the following manner:

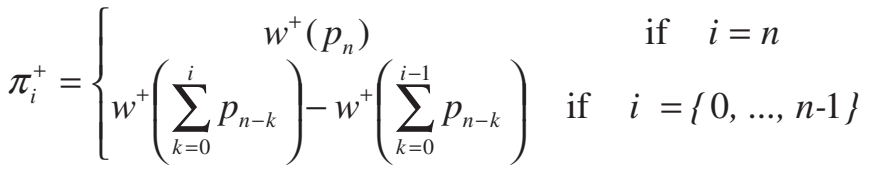

$$
\begin{aligned}
& \pi_{i}^{-}=\left\{\begin{array}{cl}
w^{-}\left(p_{-m}\right) & \text { if } i=-m \\
w^{-}\left(\sum_{k=0}^{i} p_{-(m-k)}\right)-w^{-}\left(\sum_{k=0}^{i-1} p_{-(m-k)}\right) & \text { if } \quad i=\{m-1, \ldots,-1\}
\end{array}\right.
\end{aligned}
$$

in which $w^{+}\left(w^{-}\right)$denotes a probability weighting function for gains (losses). The probability weighting function $w(p)$ is strictly increasing and maps a unit interval into itself such that $w(0)=0$ and $w(1)=1$. The parametric form of $w(p)$ was proposed along with CPT by 
Tversky and Kahneman (1992) as:

$$
w(p)=\frac{p^{\gamma}}{\left(p^{\gamma}+(1-p)^{\gamma}\right)^{\frac{1}{\gamma}}}
$$

A fair amount of attention has been given to theoretical and empirical inquiry of the probability weighting function (Camerer \& Ho, 1994; Gonzalez \& Wu, 1999; Neilson \& Stowe, 2002; Prelec, 1998; Tversky \& Wakker, 1995; Wu \& Gonzalez, 1996). All these studies converge to the conclusion that the probability weighting function has a shape of an inverted S. That is, it starts as concave and then becomes convex. There also seems to be a general agreement also that the point of inflection is below 0.5 , in particular it is between 0.3 and 0.4 . These general conclusions are robust to different parametric specifications ${ }^{5}$. In a quest to attenuate the dependence of the probability weighting function shape on the specific functional form used in parametric investigations Abdellaoui (2000) conducts a nonparametric inquiry into both the probability weighting function and the value (utility) function under CPT. Abdellaoui's (experimental) findings are in agreement with findings obtained through parametric methods in other experimental studies, including those referred to herein.

Figure 2

The shape of the probability weighting function

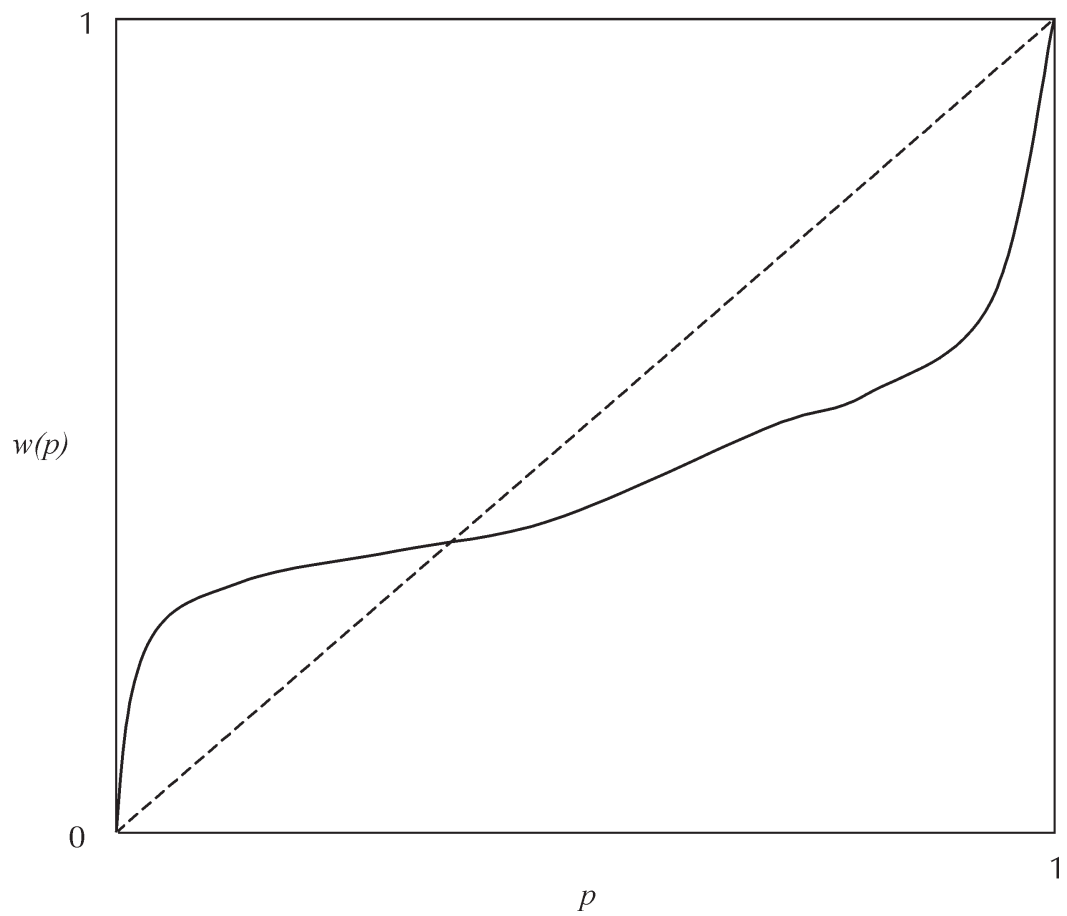

The inverted-S shape of the probability weighting function implies that people overweight low probabilities and underweight high probabilities. This pattern suggests that people are overly sensitive to changes from impossible to possible and from possible to certain but are insufficiently sensitive to probabilistic information otherwise (Tversky \& Wakker, 1995; Diecidue \& Wakker, 2001).
Inverted-S shape also predicts both optimism and pessimism. In an optimistic situation people tend to be risk seeking for gambles that yield gains with small probabilities such as is common with public lotteries. In a pessimistic situation people tend to be risk averse to gambles that yield losses with small probabilities, as is the case with insurance (Diecidue \& Wakker, 2001). 


\section{5}

\section{Prospect theory predictions}

The opening quote referred to PT as a "set of rules" due to the encompassing nature of the theory in terms of different and sometimes diverse situations that PT can explain with its many features or components that comprise the "set", applied either individually or in groups. Embodied in CPT are the features of loss aversion, diminishing sensitivity, probability weighting and narrow framing. Loss aversion is arguably the central feature of CPT if the increased attention it has received in several areas of economic research is anything to go by. Many of the predictions reported below are prevalent in riskless choice.

Samuelson and Zeckhauser (1988) report a bias of preference towards an outcome that is designated as a status quo both from the field (Havard faculty healthcare options) and from the laboratory. Johnson, Hershey, Meszaros and Kunreuther (1993) made a similar observation in a study of insurance purchases. Their study revealed that people have an exaggerated preference for whichever option is the default choice. A phenomenon of a slightly different sort is the endowment effect (Thaler, 1980) in which once a person is in possession of a good $\mathrm{s} /$ he exhibits strong reluctance to part ways with it even under appropriate incentives to do so (such as the offer to purchase the good or exchanging it for another good which is of greater value).

The three phenomena - status quo bias, default preference and the endowment effect have a common feature of determining a reference point for the individual. The reference dependence nature of CPT helps to explain the phenomena with loss aversion and diminishing sensitivity. In the case of status quo bias and default preference the factor hindering change is that of diminishing sensitivity since the change to another option is very close to the reference point (status quo or default position). In the case of endowment effect loss aversion is the main factor responsible for the phenomenon. This is particularly so because the disutility of giving up a good is greater than the utility of acquiring it. These arguments also help to understand the prevalence of brand loyalty to a particular product even when better products are available.

CPT also predicts asymmetries in the price elasticities of consumer goods due to loss aversion. Camerer (1998) reports results from studies by Putler as well as Hardie, Johnson and Fader to confirm this prediction. The catch here is that loss averse consumers dislike price increases more than they like price cuts of corresponding magnitudes. Consumers will cut back purchases more following a price increase compared to the extra amount they will buy following a price reduction.

The willingness to pay (WTP) to acquire a good and the willingness to accept compensation (WTA) to give up a good are the two measures of value in standard economic theory. While there is a disparity between these two measures due to, among other things income effects, they are often played down as not significant as shown by Knetsch and Sinden (1984:508) quoting other works positing that "...in most applications the error of approximation will be very small..." and “... practically speaking, it does not appear to make much difference which definition is adopted". The magnitude of the observed discrepancy is however large and is puzzling in standard models even after controlling for the suspected sources of disparity in an experimental setting (Knetsch \& Sinden, 1984). Tversky and Kahneman (1991) invoke loss aversion to offer a compelling and plausible explanation for this discrepancy. The individual stating the WTA is the one in a position to give up a good while the person intending to acquire it declares WTP. If there is loss aversion for the good the owner will be reluctant to sell. Equivalently if the buyer views the money spent on the purchase as a loss there will be reluctance to buy. Kahneman, Knetsch and Thaler (1990) confirmed this behaviour experimentally.

The preceding section has already noted that the coexistence of insurance and gambling (state lotteries in particular though not exclusively), which could not be rationalised in the standard framework, the EUT, follow directly from the CPT features of probability weighting and the simultaneous existence of concavity and convexity of the value function. 
Prospect theory features have also been used to provide a plausible explanation for the long standing equity premium puzzle. The high excess return on stocks was declared a puzzle by the work of Mehra and Prescott (1985). Since then a considerable amount of research effort has been directed at attempting to resolve the puzzle. The robustness of the puzzle to various resolution attempts is shown by Korchelakota (1996). However ideas from PT have rendered plausible explanations to the puzzle. Benartzi and Thaler (1995) use loss aversion coupled with narrow-framing to offer a convincing explanation of the phenomenon. The type of narrow-framing invoked is myopia (frequent evaluation periods of stocks performance). In an award winning article, Barberis, Huang and Santos (2001) couple PT with the house money effect to explain the equity premium puzzle.

\section{6}

\section{Is a paradigm shift warranted?}

The dominant behavioural hypothesis, the EUT, is plagued with descriptive limitations despite its normative appeal. On the other hand the conceptual soundness and descriptive robustness of PT recommends it as the most appropriate hypothesis in analysis of risk in economics. PT can explain most of the basic phenomena that EUT has been fruitfully applied to like asset pricing and insurance demand. In addition PT can explain behaviour that appears anomalous to EUT. After surveying ten such anomalies from the field, Camerer (1998) comments that there is no good scientific reason why EUT should not be abandoned in favour of PT and that PT should be given prominent space in economics textbooks.

On the basis of evidence and what analysts are looking for from a theory - accurate predictions - Camerer's assertion is valid. However as in any change situation, there are trade-offs to be made. The following table communicates such tradeoffs from the perspective of strengths and weaknesses (or costs) of each of the two theories.

Table 1

A cost-benefit analysis of adoption of PT and staying with EUT

\begin{tabular}{|c|c|}
\hline Expected Utility Theory (EUT) & Prospect Theory (PT) \\
\hline \multicolumn{2}{|c|}{ Strengths } \\
\hline $\begin{array}{l}\text { 1. EUT major strength lies in its simplicity. EUT } \\
\text { preference foundations are based on a set of few } \\
\text { and standard axioms (completeness, transitivity, } \\
\text { independence, continuity, etc). } \\
\text { 2. EUT is universally applicable to all standard } \\
\text { economic problems with inherent risk. }\end{array}$ & $\begin{array}{l}\text { 1. PT is conceptually and intuitively sound and } \\
\text { tractable as a theory. } \\
\text { 2. PT satisfactorily explains all the phenomena in } \\
\text { which EUT systematically falls short. }\end{array}$ \\
\hline \multicolumn{2}{|c|}{ Weaknesses } \\
\hline $\begin{array}{l}\text { 1. The systematic descriptive shortcomings } \\
\text { highlighted: } \\
\text { a) Allais paradoxes (common consequence and } \\
\text { common ratio effects) } \\
\text { b) Failure of procedure invariance (preference } \\
\text { reversals) } \\
\text { c) Failure of description invariance (frame } \\
\text { dependence) } \\
\text { d) Incompatibility with risk aversion in modest } \\
\text { to large stake lotteries. }\end{array}$ & $\begin{array}{l}\text { 1. Axiomatization of PT can be viewed as ad hoc. } \\
\text { Different authors use different, and non standard, } \\
\text { conditions to establish explicit functional forms } \\
\text { of the PT value function. } \\
\text { 2. PT is conceptually more complex than EUT. There } \\
\text { are likely to be errors in its application that are } \\
\text { due to lack of adequate grasp }{ }^{6} \text {. } \\
\text { 3. Apart from the technical complexity that PT adds } \\
\text { to analysis, PT cannot claim universal applicability } \\
\text { to standard economic models with inherent risk } \\
\text { that EUT enjoys. For example PT preference } \\
\text { foundations are incompatible with incentive } \\
\text { compatible schemes in moral hazard models }{ }^{7} \text {. }\end{array}$ \\
\hline
\end{tabular}


The weaknesses of EUT have been highlighted elsewhere in the article. Table 1 shows that adoption of PT is not without costs. The costs of PT can be grouped into conceptual complexities and non-universality. With the former the analysis of standard problems is bound to be more complex than it already is. More complex analysis increases likelihood of such analysis not being conducted correctly. A decision has to be made whether putting up with the continued inaccuracies of EUT is preferred to embracing PT with the complexities it brings to the analysis.

Non-universality of PT application is a serious shortcoming. The solution to this problem may be not to completely abandon EUT if PT is embraced as a mainstream hypothesis. Starmer's (2000) survey article suggests that the "hunt" is still on for the descriptive theory of choice under risk, which seems to imply that the non-EU theories that have been put forth have not yet matched the "elegance and power" of EUT. This is true to some extent but on the other hand the candidate has been identified. The search can be called off on this ground and effort be directed towards refining and fine-tuning PT.

Resistance to a paradigm shift on grounds that abandoning EUT would be tantamount to nullifying a lot of work that has been done in game theory, choice in dynamic settings (rational expectations models in particular) and to some extend finance is not a valid one. Machina's (1989) paper counters the widely held view that non-EU maximizers will behave in a manner that is dynamically inconsistent. He shows that dynamic consistency implied by the EUT is a result of an implicit assumption of consequentialism, which is a dynamic version of separability, which is rejected by non-EU maximizers. It is therefore not correct to impose consequentialism on non-EU preferences. Epstein (1992) surveys some non-EU theories that have been applied successfully to standard problems in macroeconomics, finance and game theory. EUT is therefore not indispensable. PT does warrant a paradigm shift in the economics of risk, subject to economists' willingness to embrace the complexities it carries with it and EUT not being completely abandoned.

\section{7}

Summary

This article has provided an assessment of the economics of choice under risk with respect to the competing behavioral hypotheses, EUT and PT. The EUT continues to be the dominant underlying hypothesis in analysis of risk despite its well documented descriptive inaccuracies. PT has emerged among the several non-EU theories that were proposed in the wake of apparent and systematic inaccuracies of EUT as the most promising descriptive hypothesis.

A case is made for PT by way of lucidly outlining it and its descriptive predictions that extend beyond analysis of risk to other economic phenomena such as the disparity between willingness to pay and willingness to accept compensation. PT accurately describes phenomena that EUT systematically fails to predict accurately. This coupled with the fact that the work of Tversky and Kahneman has been recognized with a Nobel Prize (2002) in economics have led to several scholars (including the author) feeling that EUT should make way for PT as a mainstream behavioral hypothesis in the economics of risk.

An objective assessment of the merits and demerits of a paradigm shift in terms of the strengths and weaknesses of both EUT and PT suggests that this is a close call, not an easy one to make. EUT weaknesses remain its descriptive inaccuracies while PT weaknesses are conceptual complexity and non-universality of it application. A paradigm shift is warranted subject to economists' willingness to embrace the complexities that PT carries with it and it's fine-tuning to improve its widespread use while not completely abandoning EUT.

\section{Endnotes}

1 This article has benefited from the comments by the $9^{\text {th }}$ AES conference participants in Cape Town, the seminar participants in the Department of Economics, National University of Lesotho 
and two anonymous referees. I have also benefited from communication with Horst Zank. None of these should however be held responsible for errors and intepretations in the paper. Those are entirely my own.

2 See Machina (1987) or Schoemaker (1982) for description of the game. Alternatively see http:// plato.stanford.edu/archives/fall 2001/entries/ paradox-stpetersburg

3 In a later study by Tversky, Slovic and Kahneman (1990), intransitivity of preferences, which underpins regret as the rationale for preference reversals, accounted for only 10 percent of preference reversals observed while the remaining 90 percent was accounted for by failure of procedure invariance. Tversky et. al. point to failure of procedure invariance as the major cause of preference reversals.

4 The generality of CPT over RDU is clearly shown in this equation by observing that put another way equation (4) states that $\mathrm{CPT}=\mathrm{RDU}^{+}+$ RDU-.

5 Gonzalez and Wu (1999) investigated $w(p)=\frac{\delta p^{\gamma}}{\delta p^{\gamma}+(1-p)^{\gamma}}$ while Prelec (1998) proposed and investigated $\mathrm{w}(\mathrm{p})=w(p)=e^{-(-\ln p)^{\gamma}}$.

6 By way of comparison this is precisely the reason why most governments resist to shift from cash accounting basis to accrual accounting basis.

7 Horst Zank brought this example to my attention

\section{References}

1 ABDELlaOUI, M. (2000) "Parameter-free elicitation of utility and probability weighting functions," Management Science, 46: 14971512.

2 ALLAIS, M. (1953) "Le comportement de l'homme rationell devant le risque : Critique des postulats et axiomes de l'ecole Americaine," Econometrica, 21: 503-542.

3 BARBERIS, N.; MING, H. \& SANTOS, T. (2001) "Prospect theory and asset prices," Quarterly Journal of Economics, 116: 1-53.

4 BELL, D.E. (1982) "Regret in decision making under uncertainty," Operations Research, 30: 961-981.

5 BENARTZI, S. \& THALER, R.H. (1995) "Myopic loss aversion and the equity premium puzzle," Quarterly Journal of Economics, 110: 73-92.
6 BERNOULLI, D. (1954) "Exposition of a new theory on the measurement of risk," (original 1738) Econometrica, 22: 23-36.

7 CAMERER, C.F. (1998) "Prospect theory in the wild: Evidence from the field," Social Science Working Paper, 1037, California Institute of Technology.

8 CAMERER, C.F. \& HO, T.H. (1994) "Nonlinear weighting of probabilities and violations of the betweenness axiom," Journal of Risk and Uncertainty, 8: 167-196.

9 CAMPBELL, J.Y.; LO, A.W. \& MACKINLAY, A. (1997) The Econometrics of Financial Markets, Princeton University Press.

10 CHATEAUNEUF, A. \& WAKKER, P.P. (1999) "An axiomatization of cumulative prospect theory for decisions under risk," Journal of Risk and Uncertainty, 18: 137-145.

11 DIECIDUE, E. \& WAKKER, P.P. (2001) "On the intuition of rank-dependent utility," Journal of Risk and Uncertainty 23: 281-298.

12 EPSTEIN, L.G. (1992) "Behavior under risk: Recent developments in theory and applications," in Jean-Jacques Laffont (ed.) Advances in Economic Theory: Sixth World Congress Vol. II, Cambridge University Press.

13 FRIEDMAN, M. \& SAVAGE, L.J. (1948) "The utility analysis of choices involving risk," Journal of Political Economy, 56: 279-304.

14 GONZALEZ, R. \& WU, G. (1999) "On the shape of the probability weighting function," Cognitive Psychology, 38: 129-166.

15 GRETHER, D. \& PLOTT, (1979) "Economic theory of choice and the preference reversal phenomenon," American Economic Review, 69: 623-638.

16 GUL, F. (1991) "A theory of disappointment aversion," Econometrica, 59: 667-686.

17 HERSHEY, J.C. \& SCHOEMAKER, P.H. (1980) "Risk-taking and problem context in the domain of losses: An expected utility analysis," Journal of Risk and Insurance, 40: 111-132.

18 JIA, J.; DYER, J.S. \& BUTLER, J.C. (2001) "Generalized disappointment models," Journal of Risk and Uncertainty, 22: 59-78.

19 JOHNSON, E.; HERSHEY, J.; MESZAROS, J. \& KUNREUTHER, H. (1993) "Framing, probability distortions and insurance decisions," Journal of Risk and Uncertainty, 7(1): 35-51.

20 KAHNEMAN, D. \& TVERSKY, A. (1974) "Judgement under uncertainty: heuristics and biases," Science, 185: 1124-1131. 
21 KAHNEMAN, D. \& TVERSKY, A. (1979) "Prospect theory: An analysis of decision under risk," Econometrica, 47: 263-291.

22 KAHNEMAN, D.; KNETSCH, J.L. \& THALER, R.H. (1990) "Experimental tests of the endowment effect and the Coase theorem," Journal of Political Economy, 98: 1325-1348.

23 KNETSCH, J.L. \& SINDEN, J.A. (1984) "Willingness to pay and compensation demanded: Experimental evidence of an unexpected disparity in measures of value," Quarterly Journal of Economics, 99: 507-521.

24 KOCHERLAKOTA, N.R. (1996) "Equity premium: It's still a puzzle," Journal of Economic Literature, 34: 42-71.

25 LICHTENSTEIN, S. \& SLOVIC, P. (1971) "Reversals of preferences between bids and choices in gambling decisions," Journal of Experimental Psychology, 89: 46-55.

26 LICHTENSTEIN, S. \& SLOVIC, P. (1973) "Response-induced reversals of preferences in gambling: An extended replication in Las Vegas," Journal of Experimental Psychology, 101: 16-20.

27 LOOMES, G. \& SUGDEN, R. (1982) "Regret theory: An alternative theory of rational choice under uncertainty," Economic Journal, 92, 805824.

28 LOOMES, G. \& SUGDEN, R. (1983) "A rationale for preference reversal," American Economic Review, 73: 428-432.

29 LOOMES, G. \& SUGDEN, R. (1987) "Some implications of a more general form of regret theory," Journal of Economic Theory, 41: 270287.

30 LUCE, D. \& FISHBURN, P. (1991) "Rank- and sign-dependent linear utility models for finite first order gambles," Journal of Risk and Uncertainty, 4: 29-59.

31 MACHINA, M.J. (1987) "Choice under uncertainty: Problems solved and unsolved," Journal of Economic Perspectives, 1: 121-154.

32 MACHINA, M.J. (1989) "Dynamic consistency and non-expected utility models of choice under uncertainty," Journal of Economic Literature 27, 1622-1688.

33 MACHINA, M.J. (1994) "Review of Generalized expected utility theory: the rank-dependent model by John Quiggin (1993) Kluwer Academic Publishers," Journal of Economic Literature, 32: 1237-1238.

34 MEHRA, R. \& PRESCOTT, E.C. (1985) "The equity premium: A puzzle," Journal of Monetary Economics, 15: 145-161.
35 MORRISON, D. (1967) "On the consistency of preferences in Allais' paradox," Behavioral Science, 12: 373-383.

36 MOSKOWITZ, H. (1974) "Effects of problem presentation and feedback on rational behavior in Allais and Morlat-type problems," Decision Sciences, 5: 225-242.

37 NEILSON, W. \& STOWE, J. (2002) "A further examination of cumulative prospect theory parameterizations," Journal of Risk and Uncertainty, 24: 31-46.

38 PRELEC, D. (1998) "The probability weighting function," Econometrica, 66: 497-527.

39 QUIGGIN, J. (1982) "A theory of anticipated utility," Journal of Economic Behaviour and Organization, 3: 323-343.

40 RABIN, M. (2000) "Risk aversion and expected utility theory: A calibration theorem," Econometrica, 68: 1281-1292.

41 RABIN, M. \& THALER, R.H. (2001) "Anomalies: Risk aversion," Journal of Economic Perspectives, 15: 219-232.

42 SAMUELSON, P.A. (1963) "Risk and uncertainty: A fallacy of large numbers," Scientia, 98: 108-113.

43 SAMUELSON, W.F. \&. ZECKHAUSER, R.J. (1988) "Status quo bias in decision making," Journal of Risk and Uncertainty, 1: 7-59.

44 SCHMIDT, U. (2003) "Reference-dependence in cumulative prospect theory," Journal of Mathematical Psychology, 47: 122-131.

45 SCHMIDT, U. \& ZANK, H. (2002a) "Risk aversion in cumulative prospect theory," School of Economics Discussion Paper: University of Manchester.

46 SCHMIDT, U. \& ZANK, H. (2002b) “An axiomatization of linear cumulative prospect theory with applications to portfolio selection and insurance demand," School of Economics Discussion Paper: University of Manchester.

47 SCHOEMAKER, P.H. (1982) "The expected utility model: Its variants, purposes, evidence and limitations," Journal of Economic Literature, 20(2): 529-563.

48 SEGAL, U. (1988) "Probabilistic insurance and anticipated utility," Journal of Risk and Insurance, 55: 287-297.

49 SHUMWAY, TYLER (1997) "Explaining returns with loss aversion," University of Michigan Business School working paper.

50 SLOVIC, P. \& TVERSKY, A. (1974) "Who accepts Savage's axiom?” Behavioral Science, 19: 368-373. 
51 STARMER, CHRIS (2000) "Developments in the non-expected utility theory: The hunt for a descriptive theory of choice under risk," Journal of Economic Literature, 38: 332-382.

52 STARMER, C. \& SUGDEN, R. (1989) "Violations of the independence axiom in common ratio problems: An experimental test of some competing hypotheses," Annals of Operational Research, 19: 79-102.

53 THALER, RICHARD H. (1980) “Toward a positive theory of consumer choice," Journal of Economic Behavior and Organization, 1: 39-60.

54 TVERSKY, A. \& KAHNEMAN, D. (1981) “The framing of decisions and the psychology of choice," Science, 211: 453-458.

55 TVERSKY, A. \& KAHNEMAN, D. (1986) "Rational choice and the framing of decisions," Journal of Business, 59: s251-s278.

56 TVERSKY, A. \& KAHNEMAN, D. (1991) "Loss aversion in riskless choice: A referencedependent model," Quarterly Journal of Economics, 106: 1039-1061.

57 TVERSKY, A. \& KAHNEMAN, D. (1992) "Advances in prospect theory: cumulative representation of uncertainty," Journal of Risk and Uncertainty, 5: 297-323.
58 TVERSKY, A.; SLOVIC, P. \& KAHNEMAN, D. (1990) "The causes of preference reversals," American Economic Review, 80: 204-217.

59 TVERSKY, A. \& THALER, R.H. (1990) "Anomalies: Preference reversals," Journal of Economic Perspective, 4(2): 201-211.

60 TVERSKY, A. \& WAKKER, P.P. (1995) "Risk attitudes and decision weights," Econometrica, 63: $1255-1280$.

61 VON NEUMANN, J. \& MOGENSTERN, O. (1944) Theory of Games and Economic Behaviour, Princeton University Press.

62 WAKKER, P.P. \& TVERSKY, A. (1993) "An axiomatization of cumulative prospect theory," Journal of Risk and Uncertainty, 7: 147-176.

63 WAKKER, P.P. \& ZANK, H. (2002) "A simple preference foundation of cumulative prospect theory with power utility," European Economic Review 46: 1253-1271.

64 ZANK, H. (2002) "Cumulative prospect theory for parametric and multiattribute utilities," Mathematics of Operations Research 26: 67-81. 